Maruša PUŠNIK, Dejan JONTES*

\title{
MEDIJI IN SPONTANI NACIONALIZEM: PRIMER MELANIE TRUMP**
}

\begin{abstract}
Povzetek. Clanek analizira reprezentacije Melanie Trump $v$ slovenskih tiskanih medijih in raziskuje, kako je bil v prispevkih o Melanii Trump konstruiran spontani nacionalizem, ta pa je bil v medijih povezan s promocijo slovenske nacije prek Melanie kot blagovne znamke. Moč nacionalnih vezi, idej in tradicije je namreč vzdrževana in redistribuirana prek medijev in popularne kulture, zato avtorja $v$ nasprotju z literaturo s tega področja, ki medije večinoma obravnava le kot mediatorje, $v$ članku tudi kritično naslavljata vprašanje vloge medijev v procesu znamčenja nacije in jih obravnavata kot neodvisne akterje. Avtorja analizirata 594 prispevkov o Melanii Trump, objavljenih $v$ slovenskih tiskanih medijih v obdobju treh mesecev v letih 2016 in 2017. Analiza tiskanih medijev $v$ Sloveniji je pokazala, da številne in ponavljajoče se medijske reprezentacije "Melanie "potiskajo slovenski nacionalizem $v$ komercialni kontekst in posledično transformirajo nacijo $v$ blago.

Ključni pojmi: medijski diskurz, komodifikacija, Melania Trump, prva dama, nacionalizem, znamčenje nacije
\end{abstract}

\section{Uvod}

Članek uporablja primer Melanie Trump, nekdanje prve dame ZDA, da bi analiziral diskurzivne strategije, prek katerih so tiskani mediji v Sloveniji nacionalistično reprezentirali »Melanio« kot etnično rojeno Slovenko. Zaradi zelo tekmovalnega globalnega ekonomskega okolja se države dandanes s pomočjo medijev pogosto predstavljajo kot blagovne znamke in vse to kliče

* Dr. Maruša Pušnik, izredna profesorica, Fakulteta za družbene vede, Univerza v Ljubljani, Slovenija; dr. Dejan Jontes, izredni profesor, Fakulteta za družbene vede, Univerza v Ljubljani, Slovenija.

** Izvirni znanstveni članek.

Raziskava, predstavljena $v$ tem članku, je bila izvedena v okviru nacionalnega raziskovalnega programa Družbena pogodba $v$ 21. stoletju (P6-0400, 2015-2025), ki ga financira Javna agencija za raziskovalno dejavnost Republike Slovenije.

DOI: 10.51936/tip.58.2.464-480 
po ponovnem premisleku o konceptu nacionalizma. ${ }^{1} \mathrm{~V}$ tem oziru Castelló in Mihelj (2018) zatrjujeta, da trenutna oživitev nacionalnega presega področje politike, saj je le-to bolj zasidrano v logiki globalnega kapitalizma in je tako postalo neločljivo povezano s praksami promocije in potrošnje. Omenjata več razprav, ki so se pojavile v okviru različnih tem, od »ekonomskega nacionalizma«, "znamčenja nacije«, "potrošniškega etnocentrizma« do »komercialnega nacionalizma«. Vidmar Horvat (2019) govori o preobratu procesov od sodobne etnizacije nacije do postmodernega trženja nacije, ko opisuje postmilenijski nacionalizem kot korporativno idejo, pri kateri se čustveni odnosi spajajo s komercialno privlačnostjo. V zvezi s tem v članku predlagamo koncept komodificiranega nacionalizma za opis procesov, kako so slovenski mediji kreirali Melanio Trump kot slovensko nacionalno blagovno znamko.

Številni avtorji namreč poudarjajo povezavo med nacionalizmom in trženjem v sodobnem svetu. Na primer, Aronczyk (2013) trdi, da znamčenje nacije kot proces oblikovanja in komuniciranja nacionalne identitete uporablja orodja, tehnike in strokovna znanja iz sveta korporativnega upravljanja blagovnih znamk. Poleg tega Hoefte in Veenendaal (2019) dodajata, da sta dandanes gradnja nacionalne države in znamčenje nacije tesno prepletena procesa, saj slednjega ni mogoče obravnavati ločeno od izgradnje nacionalne države. Znamčenje slovenske nacije prek podob »Melanie«v medijih tako vedno vključuje tudi izgradnjo zamišljene slovenske nacionalne skupnosti. Vendar pa po besedah Varge (2013) tak proces znamčenja nacije, ki vključuje tudi ekonomski vidik, kot kulturni projekt pomaga ohranjati, legitimirati in ustvarjati neoliberalni družbeni red, v katerem so vsi kulturni fenomeni videni in obravnavani skozi ekonomsko perspektivo. Tržno znamčenje nacije torej na nek način izpodriva stari etnonacionalizem in ga zamenjuje z novo obliko tržno vsidranega nacionalnega upravljanja podob (Bolin in Miazhevich, 2018). Takšno marketinško orodje - znamčenje nacije je še posebej aktivno na ozemlju vzhodnoevropskih držav in tudi v Sloveniji kot delu nekdanje Jugoslavije (glej Volčič, 2008; Konečnik Ruzzier, 2012; Vitic in Ringer, 2007; Szondi, 2007; Jansen, 2008; Kania-Lundholm, 2012; Volčič in Andrejevic, 2011), saj so morale te države intenzivno poiskati svojo koherentno nacionalno identiteto in nacionalno pripadnost, zato so v mnogih primerih aktivirale, kot pravi Volčič (2008), "projekte nacionalnega znamčenja države«. Prav tako tudi Kaneva in Popescu (2011) trdita, da so napori postkomunističnih držav (za primer vzameta Romunijo in Bolgarijo), da bi ponovno iznašli nacionalne podobe prek rabe nacionalnega znamčenja, še večji, saj so te države po padcu komunizima občutile globoko potrebo po

1 Po devetdesetih letih dvajsetega stoletja je znamčenje nacije pritegnilo veliko pozornost tako raziskovalcev na eni strani kot vladnih akterjev na drugi strani, zatrjujeta Bolin in Miazhevich (2018: 527). 
nacionalni redefiniciji. To pa je šlo $\mathrm{z}$ roko $\mathrm{v}$ roki s porajanjem kapitalizma $\mathrm{v}$ teh državah. Zdi se tudi, da je znamčenje nacije bolj značilnost majhnih perifernih držav, ki morajo ubraniti svoj položaj in vlogo v primerjavi z velikimi, nadrejenimi narodi, in $\mathrm{v}$ tem pogledu se ta postmoderna gradnja nacije razlikuje od tradicionalnih modernističnih konstrukcij nacionalne države. Naš cilj analize je prikazati posebnosti tega postmodernega znamčenja slovenske nacije na primeru »Melanie«, ki je na eni strani povezana z zvezdniškim nacionalizmom in na drugi s komodifikacijo nacije. Osrednje raziskovalno vprašanje je, kako je celotno znamčenje Melanie v slovenskih tiskanih medijih $\mathrm{v}$ prvi vrsti povezano z občutki majhne in neprepoznavne nacije in kako se prek medijskih reprezentacij »Melanie« konstruira slovenska nacija kot tržno blago.

Naš primer je specifičen $\mathrm{v}$ tem smislu, da ni bilo neke skladne in dirigirane kampanje znamčenja, ampak je medijski diskurz samostojno deloval kot državotvorni in narodotvorni diskurz in je predstavljal Melanio Trump kot slovensko blagovno znamko prek spontanega izliva nacionalističnega izražanja. Mediji so tako zelo pomembna orodja v sodobnih procesih znamčenja nacije, kar ugotavljata tudi Bolin in Miazhevich (2018: 527-533). Pokažeta, da medtem ko so se kritične študije o nacionalnem znamčenju 466 primarno opirale predvsem na sociološke in antropološke teorije nacionalnosti, identitet in trgov, pa je bila, nasprotno, vloga medijev - kot institucij, sistemov in družbenih pripovedovalcev zgodb - premalo teoretizirana v odnosu do nacionalnega znamčenja. Z drugimi besedami, mediji »so bili opisani kot pasivna orodja pri orkestriranju kampanj znamčenja nacij brez lastnega akterstva" (Bolin in Stahlberg, 2015: 3066), čeprav so mediji pravzaprav sestavni del nacionalnega znamčenja, saj ohranjajo ideje, podobe, ideologije, diskurze in prakse znamčenja nacij. ${ }^{2} \mathrm{~V}$ članku ugotavljamo, da je takšna oblika znamčenja nacije sodobna oblika nacionalizma, zlasti v primeru turizma, kar pa je bilo le redko obravnavano v okviru medijskih naracij (glej Frew in White, 2011; Fan, 2006; Pamment in Cassinger, 2018; Volčič, 2011; Dinnie, 2016; Shepherd, 2002).

Cilj te študije je tako odkriti medijsko generirane podobe, da bi razumeli, kaj se dogaja z nacionalizmom v mediatiziranih potrošniških družbah. Naša analiza torej temelji na predpostavki, da se komodifikacija nacije v našem primeru odvija v dveh korakih, prvič, mediji reprezentirajo »Melanio« kot avtentično Slovenko, kot "našo"skromno, izjemno in slavno Slovenko, in drugič, "Melania« je v tem oziru predstavljena kot tista, ki "nam» lahko pomaga v ekonomskem smislu; ali rečeno drugače, "Melanio« se uporablja

2 Kim in Lee (2018) na primeru Koreje prikažeta, kako so različni kulturni akterji v državi, tudi mediji, sodelovali z nacionalnimi vladami, da bi promovirali nacionalni ponos doma in pozitivno podobo nacije $v$ mednarodnem prostoru $v$ dobi globalne kompeticije. Nacionalno znamčenje tako povežeta s procesi marketizacije, saj se je vse to odvijalo na blagounih trgih. 
za trženje slovenske nacije kot blaga. Še več, v ozadju tega kulturnega fenomena znamčenja nacije ni toliko proces narodotvorja ali neke kolektivne identifikacije bralcev z nacijo, temveč bolj banalne, vsakdanje fantazije, ki temeljijo na povzdigovanju majhnih narodov iz anonimnosti.

V analizo je bilo vključenih 594 prispevkov o Melanii Trump, objavljenih v slovenskih tiskanih medijih ${ }^{3}$ v obdobju treh mesecev v letih 2016 in 2017. Vzorčenje je bilo omejeno na določena časovna obdobja, saj smo vključili vse tiste novinarske tekste, ki so bili objavljeni med 15. oktobrom 2016 in 15. novembrom 2016, torej tri tedne pred predsedniškimi volitvami v ZDA 8. novembra 2016 in teden po volitvah, ter od 20. januarja 2017 do 20 . marca 2017 , to je dva meseca po inavguraciji 45 . predsednika ZDA, ki je potekala 20. januarja 2017. Študija je eksploratorna in temelji na širokem vzorcu novinarskih tekstov iz izbranih časovnih obdobij in predvsem nas zanimajo tudi razlike v poročanju med tema obdobjema. Vzorčenje je temeljilo na iskalnih besedah Melania Trump, opravila pa ga je osrednja slovenska tiskovna kliping agencija Kliping. V izbirnem postopku nismo ločevali med mnenji in novičarskimi prispevki in smo v analizo vključili oboje. Analiza temelji na induktivnem pristopu k podatkom, oba avtorja sta prebrala vsa besedila in sta v reprezentacijah "Melanie« s pomočjo metode tekstualne analize poskušala prepoznati glavne novinarske diskurzivne mehanizme, ki kreirajo slovensko nacijo kot blago. Pri tem je treba izpostaviti, da je v vzorcu približno enakomerno zastopan tako t. i. kakovostni kot regionalni, revijalni in rumeni tisk, skupaj prek 30 različnih publikacij. Če omenimo samo tiste z več kot 20 besedili v vzorcu, je bilo iz Dnevnika v analizo vključenih 72 člankov z omenjenimi iskanimi besedami, iz Večera 61, Dela 57, Sveta24 48, Reporterja 45, Primorskih novic 42, Slovenskih novic 34 in Mladine 23.

\section{Nacije kot komercialna podjetja in poblagovljenje nacionalnih čustev}

Roosvall in Salovaara-Moring (2010: 9) izpostavljata, da je bila nacija »kot ključna družbena kategorija « v medijskih študijih v globalni dobi podteoretizirana. Bila je eksplicitno označena kot "postnacionalna" ali »denacionalna", v razpravah o glokalizaciji je bila tudi pozabljena/prezrta, kot je bila prezrta tudi v večjem delu splošnejše globalizacijske paradigme. Lahko rečemo, da je bila nacija prezrta kot kulturno-ekonomska kategorija, zato Bolin in Ståhlberg (2010) obravnavata nove načine, kako se dandanes nacije konstruirajo v kulturnem in ideološkem smislu kot skupnost, a hkrati tudi kot

3 Po besedah B. Luthar in A. Trdina (2015: 284) priljubljeni tabloidni tedniki, ki predstavljajo pomemben del našega vzorca, še vedno ostajajo osrednji za diskurz o celebrifikaciji v Sloveniji, "čeprav se kultura slavnih diseminira $v$ široki paleti popularne kulture in medijskih žanrov v starih in novih medijih, je težko zamejiti njene meje». 
blago. Poudarjata, da sodobne nacionalne države vedno bolj delujejo kot komercialna podjetja, ki svojo novo nacionalistično retoriko usmerjajo k mednarodnemu občinstvu investitorjev in turistov. Castile (1996: 743) citira Wallerstina, ki pravi, da je že sam zgodovinski razvoj kapitalizma vključeval procese komodificiranja »vsega», kar je vključevalo tudi formiranje trga za etnonacionalne identitete. Valaskivi (2016) v tem oziru uvaja koncept »cool nacij«, da bi opisala vlogo medijev pri družbenem imaginiranju oznamčenih držav v kapitalističnih družbah, kjer je »biti cool« centralnega pomena.

Zato lahko parafraziramo Bolina in Ståhlberga (2010) in ugotovimo, da praksa znamčenja na primeru »Melanie« konstituira solidarnost v odnosu do nacije, kot to počne nacionalizem, sočasno pa takšno znamčenje nacije uporablja kulturne tehnologije za konstitucijo nacije kot blaga. To pa proizvaja nacijo kot neoliberalno nacijo, saj se znamčenje kvalitativno razlikuje od zgodnejših oblik zamišljanja nacionalnih skupnosti. Tako se nacija vse bolj transformira iz političnega koncepta $\mathrm{v}$ komercialni produkt in postaja orodje za trženje blaga potencialnim kupcem (Ståhlberg in Bolin, 2016: 274). ${ }^{4} \mathrm{Na}$ ta način se nacijo zreducira na blago in je posledično komercializirana tudi v medijih, od televizije do tiskanih oglasov in turističnih letakov. Tak komercialni nacionalizem se tako vedno bolj uporablja za pro468 dajo izdelkov - nacij, da bi, v našem primeru, slovenski narod postal bolj prepoznaven. Gray (2007) k temu vidiku dodaja še kulturno komponento, ko govori predvsem o komodifikaciji nacionalne "kulture« za "nekulturne" namene, $\mathrm{v}$ tem primeru za politične narodotvorne projekte države (glej tudi Heller (2010) za podobno tezo o komodifikaciji nacionalnega jezika kot kulturnega artefakta za promocijo nacije).

$\mathrm{Na}$ podlagi številnih nedavnih razprav $\mathrm{v}$ članku pokažemo, da je »Melania« v medijih diskurzivno konstruirana kot slovenska nacionalna blagovna znamka in da pri reprezentiranju slovensko-ameriških odnosov takšna blagovna znamka promovira ekonomsko vrednost in večjo prepoznavnost majhnega slovenskega naroda, kar bi Slovenijo lahko umestilo na širši globalni zmeljevid. Po mnenju Bolina in Miazhevicha (2018: 527) take kampanje znamčenja nacije ustvarjajo ahistorične in ekskluzivistične reprezentacije nacije in pospešujejo obliko »komercialnega nacionalizma«, ki je zelo problematičen. Sledeč Baudrillardu Kaneva (2018: 631) trdi, da lahko nacionalne blagovne znamke vidimo kot simulakre, ki obstajajo $\mathrm{v}$ transnacionalnem sistemu za ustvarjanje, kroženje in porabo takšnega blaga - znakov. »Melania k kot nacionalna blagovna znamka tako deluje kot blago - znak. V tem oziru Kaneva (2018: 631) dodaja, da nacionalne blagovne znamke nosijo reprezentacijsko breme, da stojijo za nacijo kot celoto. $\mathrm{Z}$ besedami

4 Ta praksa se pogosto uporablja ne samo v turističnem sektorju, temveč tudi v gospodarskem in političnem sektorju obstoječih nacionalnih držav. 
Z. Volčič in Andrejevica (2011) lahko ugotovimo, da slovenski mediji zlorabljajo "Melanio" za razširjanje nacionalnih interesov in za spodbujanje občutka lojalnosti in pripadnosti. V zvezi s tem lahko rečemo, da je znamčenje nacije praksa, ki apelira na državljane, vključuje jih kot aktivne potrošnike in proizvajalce znamke ali, če parafraziramo Z. Volčič in Andrejevica (2011), slovenski državljani občutijo »Melanio« kot nacionalno blagovno znamko, kar pomeni, da se identificirajo z njo in se vedejo v skladu s strategijo tega znamčenja.

Poleg tega praksa znamčenja »Melanie«kot nacionalne blagovne znamke v medijih vključuje konstrukcijo globokih nacionalnih čustev do »Melanie« kot Slovenke in ta čustva se nato uporablja za konstrukcijo vezi in občutenj slovenstva na eni, notranje-nacionalni strani s pomočjo medijskega grajenja idola, in na zunanji strani za trženje slovenskega naroda kot privlačnega potrošniškega izdelka na lokalnih in globalnih trgih. Nacionalna čustva so torej poblagovljena za namene trženja slovenske nacije; to ustvarja tesne vezi med vsemi državljani, ki si delijo ta isti sentiment o tem, da je "Melania" Slovenka tako kot oni. Te globoke vezi in občutki ljubezni do lastne domovine so povezani bodisi z etničnimi koreninami, kulturno dediščino, zgodovinskimi vidiki bodisi s političnimi značilnostmi (glej Nussbaum, 2010; Bodnar, 1994; Tan, 2004).

Naša predpostavka torej je, da se v slovenskih medijih oblikuje posebna vrsta komodificiranega nacionalističnega gibanja (prim. Lahusen, 1993), ko se reprezentira »Melanio « kot etnično rojeno Slovenko, kot osrednjo predstavnico slovenskega naroda in tesno povezano s slovensko zemljo. Ali če parafraziramo Ståhlberga in Bolina (2016), ima »Melania« dve funkciji v slovenskih medijih: 1.) deluje kot nacionalni označevalec za nadzor in discipliniranje prebivalstva države in za krepitev kolektivnega nacionalnega občutenja skupnosti med državljani nekega naroda, 2.) hkrati deluje tudi kot trženjsko orodje za promoviranje nacije kot privlačnega blaga za lokalno in mednarodno občinstvo. Menimo, da je druga funkcija veliko močnejša v slovenskih medijih, še posebej za namene dvigovanja slovenskega naroda iz njegove anonimnosti in majhnosti s pomočjo "Melanie». Balabanis in drugi (2001) namreč trdijo, da se v sodobnih potrošniških družbah pojavlja močan vpliv nacionalizma kot predhodnika potrošniškemu etnocentrizmu. Ta nova vrsta slovenskega komodificiranega nacionalizma, ki temelji na reprezentacijah "Melaniinega« avtentičnega slovenstva, goji občutek ljubezni, predanosti in občutek navezanosti na slovensko nacijo ter vzpostavlja vezi med državljani, ki si delijo ta isti sentiment - občudovanje »Melanie« in posledično občudovanje Slovenije. V nadaljevanju članka se osredotočamo na novinarske diskurzivne strategije znamčenja »Melanie« za komercialno-nacionalne namene. 


\section{Reprezentacije slovenskih korenin »Melanie«}

Najbolj pogosta praksa konstruiranja »Melanie« kot slovenske nacionalne znamke $\mathrm{v}$ tiskanih medijih je povezana $\mathrm{z}$ reprezentacijo in konstrukcijo Melanie Trump kot avtentične Slovenke, rojene v Sloveniji - „Slovenka v Beli hiši« (Reporter, 14. 11. 2016: 46). Večkrat lahko zasledimo navedbe, da s pomočjo Melanie Trump Slovenija vstopa v Belo hišo. Na primer v prispevku: "Če je res, da ženska podpira tri vogale vsake hiše, potem bo Slovenka že čez dobra dva meseca podpirala tri vogale najvplivnejše hiše na svetu, tiste Bele v Washingtonu. Slovenija na hrbtu Štajerke Melanije Knavs jaha med svetovne supersile! (Utenkar, Nedelo, 13. 11. 2016: 9) Tovrstne reprezentacije "Melanie« izpostavljajo državo njenega rojstva in, kar je še pomembneje, njene avtentične slovenske korenine. Če parafraziramo Eadeja (1990), medijski diskurzi na lokalni in bolj globalni ravni spodbujajo artikulacijo primordialne, nacionalne solidarnosti, ki ustvarijo vez med Slovenci. Še več, Slovenija je nenehno enačena $\mathrm{z}$ »Melanio«, s tem ko je Melaniina avtentična slovenskost reprezentirana skozi njen rojstni kraj, etnične korenine itd., pa so v ospredje tovrstnega nacionalnega "prizadevanja za avtentičnost" (Eade, 1990: 493) postavljeni občutki ponosa in istosti. Pogosto je izpostavljen ponos: »Nova

470 prva dama ZDA je na včerajšnji inavguraciji blestela kot prava dama. Slovenija je ponosna nate, Melania!« (Svet24, 21. 1. 2017) ali: „V Belo hišo s Trumpom prihaja prva dama, Slovenka, Sevničanka Melania. To pa ni kar tako in na to bi morali biti ponosni« (Šurla, Reporter, 14. 11. 2016: 3). Učinek tovrstnega medijskega poročanja je $\mathrm{z}$ drugimi besedami "prioritizacija partikularne identitete«, medijski diskurz pa je v tem primeru tesno povezan s političnim diskurzom - nacionalističnim diskurzom, zato je treba medijski diskurz umestiti "znotraj političnih diskurzov in praks, ki ustvarjajo povezavo med ljudmi kot člani 'zamišljene skupnosti'» (Eade, 1990: 493). Vendar pa je osebni ponos transformiran $\mathrm{v}$ nacionalni ponos, ko lahko bralci kot osebe vidijo njihovo celotno skupnost v medijskem diskurzu o koreninah »Melanie«:

Če slovenskim rokometašem ni uspelo zasesti samega vrha sveta, pa je to uspelo slovenski lepotici Melanii Trump. Ko je njen mož Donald prisegel kot 45. predsednik ZDA, je postala prva na tujem rojena prva dama ZDA po letu 1829. Vsekakor ji gre priznati, da je prvo nalogo $v$ novi vlogi, ki jo je morala opraviti, opravila $z$ odliko. Tako njen izbor čudovite obleke, podpisane z Ralph Lauren, kot njena drža na inavguraciji sta kazala, da je svoji novi vlogi za zdaj kos, na kar še v predvolilni kampanji ni kazalo. (Obrazi, 9. 2. 2017: 8)

V tem smislu je »Melania« tudi utelešena kot Slovenka, kot slovenski pa so poudarjeni deli njenega telesa kar lahko izzove globoka nacionalistična čustva: 
/.../ obstaja možnost, da dobimo prvo damo, da Belo hišo okupira slovenska nožica (v vrtoglavo visokih petkah). Kako se bomo lahko šopirili, če se bo to zgodilo! (Vklop, 20. 10. 2016, Marjana Vovk)

Kot trdita Pamment in Cassinger (2018), tovrstne medijske strategije pomagajo spodbujati participacijo državljanov pri promociji slovenskih vrednot, deloma z namenom pokazati avtentično plat države in deloma za ustvarjanje publicitete. V našem vzorcu je s takšnim avtentičnim nacionalnim interesom povezana skrb za materni jezik. »Melania« je v številnih člankih prikazana kot mati naroda, saj je reprezentirana ne le kot dobra mati, ampak tudi kot dobra mati naroda, kot nekdo, ki ga ne skrbi le za svoje naslednike, pač pa za celoten narod:

Mladenka iz Sevnice je kot nekakšna kraljica Estera postala prva dama $v$ Beli hiši, $v$ domu ameriškega predsednika Trumpa. Melanio Trump cenim zaradi tega, ker je svojega sina naučila govoriti slovensko.

(Turinek, Reporter, 14. 11. 2016)

Žrtvovanje za sina in medtem tudi za narod je pogosta strategija prikazovanja »Melanie« kot matere naroda ali - z besedami Ramaswamyja (2010) - »boginje naroda«. V medijih je izpostavljeno, da niti v ZDA ni pozabila na slovenske korenine, takšne reprezentacije "Melanie« pa so uporabljene kot zgled za slovenske bralce. Prikazana je kot primer najboljše mame ter obenem lepe ženske, tovrstne ponavljajoče se reprezentacije v medijih pa jo vzpostavljajo kot posebne vrste zvezdo:

Že pred meseci, ko so večinski svetovni mediji hoteli narediti Trumpu škodo in so objavili slike 20 let mlajše napol gole Melanije, sem napovedal, da so mu naredili uslugo. Manekenka Melanija se je v teh 20 letih še polepšala, in ko je Trump nagovarjal volivce, da bo Ameriko naredil boljšo, torej tudi lepšo, mu je večina najbrž verjela, kajti človek, ki je po poroki še polepšal svojo ženo, mora že znati polepšati tudi ZDA. (Sajovic, Reporter, 14. 11. 2016: 16, poudarki dodani)

Kot sta pokazali Luthar in Trdina, je v popularnih medijih diskurz etničnega nacionalizma tesno povezan s spolom in vprašanjem družbenih distinkcij. Trdita, da moč tradicionalnih nacionalnih ceremonij in spektakularnih medijskih dogodkov pri uprizarjanju nacije dopolnjujejo popularnokulturne forme (Luthar in Trdina, 2015: 265). »Melania« kot slavna oseba, manekenka, skrbna mati in prva dama - »Prva prava slovenska prva dama (Nedelo, 13. 11. 2016: 5) - je prikazana kot superženska, to pa je povezano z njenimi slovenskimi koreninami. To je denimo razvidno tudi iz prispevka 
o »darilih iz domovine $z$ za »Melanio«: »Pergerjevi se z Melanio niso nikoli osebno srečali, a po tem, koliko ji pomenijo njihovi izdelki, so prepričani, da je ponosna na to, da je Slovenka« (Nedelo, 13. 11. 2016: 5).

Tovrstni prostori slavnih, ki so uporabljeni za nacionalistične namene (glej tudi O'Connor, 2012) v slovenskih medijih konstruirajo »Melaniino«slovenskost tudi skozi uporabo tradicionalnih ritualov in praks, kot je denimo slovenska himna, ki jo je bralec spremenil na način, da je besedilo vsebovalo "Melanio" in njen rojstni kraj Sevnico, vse skupaj pa je objavil desno usmerjen politični tednik (Reporter, 6. 2. 2017b: 58). Če sledimo Nussbaumu (2010), lahko ugotovimo, da ti poetični verzi o »Melanii« kot Slovenki sprožajo globoka čustva do domovine, pri čemer so »Melaniine« etnične korenine povezane s slovenskim kulturnim izročilom in zgodovinskimi vidiki. Tovrsten nacionalizem se torej napaja tako iz popularnih diskurzov (zvezdniški diskurz) kot tradicionalnih diskurzov (najpomembnejši slovenski pesnik, državna himna). Učinek je, da se lahko bralci identificirajo s takšno slavno osebo, kot je »Melania«, ko je predstavljena kot »lepo dekle iz Sevnice«.

\section{Reprezentacije rasti slovenske ekonomije in spontani nacionalizem}

Da bi prikazali prepletanje nacionalizma in ekonomskega življenja (Castelló in Mihelj, 2018) na primeru "Melanie«, lahko ugotovimo, da tiskani mediji v Sloveniji kontinuirano reproducirajo potrošniški nacionalizem, kot ga izpeljeta Castelló in Mihelj (2018). Ta temelji tako na zavestnih nacionalističnih diskurzih in praksah kot na bolj banalnih, vsakdanjih oblikah nacionalizma. Najpogostejša novinarska diskurzivna strategija tu je združevanje slovenskih nacionalističnih diskurzov z ekonomskimi učinki »Melanie» kot prve dame, torej s potencialno rastjo slovenske ekonomije zaradi njenega položaja $v$ ameriški politiki. $V$ tednu po volitvah so skoraj vsi v vzorec vključeni mediji objavili prispevke o potencialnih ekonomskih pridobitvah Slovenije. Za Donalda Trumpa so skovali izraz »slovenski zet«, njegovo poslovno ozadje pa je bilo pogosto omenjano v kontekstu možnih investicij ameriških podjetij v Slovenijo. Številni članki v tiskanih medijih tako združujejo etnocentrizem in ekonomsko rast, ko trdijo, da "Melaniine« slovenske korenine in njena dosledna nacionalna zavednost vplivata na slovensko ekonomijo in pospeševanje slovensko-ameriških odnosov. Na primer:

Jure Stojan, direktor raziskav in razvoja na Inštitutu za strateške rešitve, je izračunal, da je Slovenija že imela korist od Melanie Trump. /.../ Povečanje je 23-odstotno, Stojan, nekdanji novinar Večera, pa ta ekonomski pojav imenuje Melania effect oziroma učinek Melanije. (Finance, 10. 11. 2016: 3) 
Tovrsten »učinek Melanie« je primer spontanega nacionalizma v tiskanih medijih in je sodeč po Aronczyku (2013) praksa znamčenja nacije, ki je uporabljena za dojemanje nacije kot uporabnega vira v naraščujoči konkurenčnosti za globalne investicije, poslovanje in turizem. V našem primeru spontane prakse znamčenja nacije v medijih temeljijo na treh osnovnih strategijah, na simbolnem združevanju bralcev, internacionalizaciji Slovenije in potrošnji »Melanie«: »Docent s katedre za mednarodne odnose na FDV Boštjan Udovič odločno pove, da je pomembno, ali bo Slovenija znala izkoristiti dejstvo, da bo prva dama Slovenka. /.../ Gre za promocijo države kot blagovne znamke. /.../S pragmatičnim pristopom, je prepričan, lahko vsaj kaj pridobimo: Morda tudi investicije." (Večer, 14. 11. 2016b: 2). Če parafraziramo Wanga (2006), lahko rečemo, da so tiskani mediji in potrošniki/bralci znova odkrili in priklicali močna nacionalistična občutenja, podkrepljena z Melaniinim položajem v Beli hiši. Vloga medijev je zvedena na promocijo etničnih povezav na notranji, nacionalni strani in ekonomsko priznanje na zunanji, globalni strani: »Trumpova administracija se bo manj ukvarjala z Evropo in bolj z rastočimi trgi. Posebnega odnosa s Slovenijo ni pričakovati, lahko pa bi slovenski menedžerji izkoristili popularnost in prepoznavnost Melanie Trump pri sklepanju poslov.« (Primorske novice, 20. 1. 2017: 11; poudarki dodani).

Izhajajoč iz tovrstnih primerov menimo, da je takšen potrošniški nacionalizem, ki se pojavlja v analiziranih tiskanih medijih, neodvisen od organiziranih državnih marketinških kampanj, je hkrati banalen in spontan, saj je kombinacija (re)produkcije slovenske nacionalne tradicije, konstrukcije slovenske identitete in, kot je pokazal Li (2009) na primeru Kitajske, potrošniškega etosa v globaliziranem kontekstu. »Melania« je, prvič, konstruirana kot slovenski produkt, nato je oglaševana $\mathrm{v}$ medijih kot slovenska nacionalna znamka in je nato, tretjič, prodana bralcem kot nacionalni potrošniški artefakt. Takšna kombinacija potrošniškega in nacionalističnega etosa omogoča bralcem identifikacijo z »Melanio« in narodom ter »občutenje opolnomočenja« (Li, 2009: 435).

Je Melania Trump res samo ženska, ki je nespretno ukradla govor Michelle Obama, ali je to ženska, ki pomeni priložnost za Slovenijo? /.../ Naša dežela torej lahko izkoristi dejstvo, da je nekdanja manekenka prišla tako daleč. Če se zgodi, da se bo preselila tudi v Belo hišo, bo to lahko za nas odlična promocija - če si le ne bomo vsega slovesa zapravili že sami z nenehnim kritiziranjem. (Grazia, 1. 11. 2016: 31)

Nekateri prispevki v našem vzorcu ostajajo na eksplicitni ravni skeptični do resničnega učinka »Melanie« na slovensko politiko in ekonomijo, vendar pa implicitno predlagajo, da lahko »Melania« pomaga tržiti Slovenijo 
kot prepoznavno znamko, ta medijska strategija pa omogoča bralkam in bralcem sanjarjenje o skupnih koreninah $z$ »Melanio « ter o njeni pomoči pri izboljševanju položaja Slovenije na globalnem zemljevidu:

\begin{abstract}
Dejstvo je, da je Sevničanka Melania Trump za prepoznavnost Slovenije $\check{z}$ e zdaj naredila toliko kot še nihče pred njo, kar se med drugim že kaže v povečanem številu ameriških turistov pri nas. Toda kaka večja pričakovanja, da se bosta zaradi Slovenke v Beli hiši v "majhni in lepi" državici na sončni strani Alp cedila med in mleko, so precej naivna. (Reporter, 23. 1. 2017a: 3)
\end{abstract}

Takšen častivreden etnonacionalizem, ki ga reproducira medijski diskurz, je tesno povezan s potrošništvom in, če parafraziramo Edensorja (2002), lahko ugotovimo, da "Melania« kot kulturna ikona reproducira in transformira občutek nacionalne identitete v Sloveniji v skladu z marketinškimi diskurzi. Ta mediatizirana konstrukcija etnocentrizma je povezana s komercialnimi vidiki, ta tip potrošniškega nacionalizma pa bi lahko po Prideauxju (2009) imenovali "vsakdanji nacionalizem«, kjer igrajo pomemben del spontane marketinške strategije medijev pri pomociji Slovenije.

\title{
Reprezentacije »Melanie« kot turističnega magneta in poblagovljenje države
}

Tretja najpogostejša diskurzivna strategija v našem vzorcu je znamčenje "Melanije kot lokalne in nacionalne turistične znamke. Skozi to strategijo je država poblagovljena, da bi postala zanimiva za potencialne obiskovalce - turiste in investitorje. Tukaj zaseda posebno mesto Sevnica, njen domači kraj, saj ta postane lokalna tržna znamka, hkrati pa predstavlja celo Slovenijo. Lokalni podjetniki so tako pričeli tržiti celo vrsto izdelkov pod znamko prve dame, od vina in čokolade do copat in tradicionalnih klobas; ti izdelki pa so bili denimo pogosto opremljeni s prestižno embalažo, napisi »Prva dama« $z$ zlatimi črkami in podobno. Najbolj prodajan tabloid je tako poročal:

V času, ko je prisegal novi ameriški predsednik Donald Trump in je sevniška rojakinja Melania postala prva dama Amerike, so v Sevnici potekali dnevi odprtih vrat, na katerih so številnim novinarskim ekipam z vsega sveta predstavljali domače blagovne znamke in lepote krajev, $v$ katerih rastejo tako lepa (in uspešna) dekleta. (Slovenske novice, 24. 1. 2017: 10)

Kot kompleksen in nastajajoč fenomen takšen popularen, banalen in vsakdanji populizem $v$ medijih predstavlja tudi resne izzive mednarodnim 
tržnikom, pri čemer področje turizma ni nobena izjema (glej denimo Cheng in Ipkin Wong, 2014). Številni naslovi in članki govorijo o potencialni »invaziji« turistov - »Tuji turisti bodo drli v Sevnico« (Slovenske novice, 10. 11. 2016: 2) - še več, Sevnica je enačena z »Melanio« - "Ameriško jutro v Melanijini Sevnici«(Večer, 10. 11. 2016a: 24). Takšen banalni medijski nacionalizem lahko nadomešča bolj organizirane turistične ali državne strategije trženja, njihov cilj pa je privabiti čim več turistov in investitorjev. Pri označevanju »Melanie« kot Slovenke je običajno uporabljana množina, s čimer je še dodatno konotirana »našost«»Melanie«, kot denimo v primeru:

Zgodilo se je, kar smo decembra 1999 objavili v Slovenskih novicah: Gola Slovenka prva dama ZDA? V članku s tem naslovom smo pisali o Donaldu Trumpu, ki se je po dveh propadlih zakonih do ušes zaljubil v našo Sevničanko, ki je bila tistikrat med vrhunskimi svetounimi manekenkami /.../ Melania Trump, rojena Melanija Knavs, je postala prva dama ZDA! (Slovenske novice, 10. 11. 2016: 2)

Fan (2006) trdi, da se moramo vprašati, kaj natančno je znamčeno, ko govorimo o znamčenju nacije. $V$ našem primeru postane nacionalna znamka $\mathrm{v}$ medijih "Melania« sama in v tem smislu njene reprezentacije pripomorejo $\mathrm{k}$ promoviranju slovenske pokrajine in kulture, od kuliniričnih do zgodovinskih in ostalih doma narejenih izdelkov. Med inavguracijo njenega moža je bila »Melania« uporabljena v medijih kot tržna znamka, ki označuje lokalnost in nacionalnost - »Številni Slovenci ne skrivajo ponosa, da je prva dama ZDA postala njihova sorojakinja, še posebej so nad dejstvom navdušeni v njeni rodni Sevnici, kjer, kakopak, kanijo iz priložnosti čim več iztržiti« (Saša Eržen, Mladina, 20. 1. 2017: 54). Nedvomno je »Melania«v medijih ustvarjena kot slovenski nacionalni simbol in, če parafraziramo Bolina in Miazhevicha (2018), takšna mehka moč komercializiranega nacionalizma v medijih poveže bralce $\mathrm{v}$ zamišljeno slovensko skupnost na eni strani, na drugi strani pa predstavlja Slovenijo in njeno lokalnost - Sevnico na globalnem zemljevidu nacionalnih držav. Po inavguraciji Donalda Trumpa so Slovenijo obiskali številni tuji novinarji in v tiskanih medijih so bila objavljena številna nekritična poročila o tem:

Zaradi prisege novega ameriškega predsednika so se na pozornost svetovne javnosti pripravili tudi v Sevnici, rojstnem kraju nove prve dame ZDA Melanie Trump. Ta konec tedna pričakujejo številne tuje novinarje, ki bodo $v$ svet ponesli tudi glas o priznanih sevniških blagovnih znamkah. Zanimanje tuje javnosti so zadnje dni pritegnili zlasti novi kulinarični izdelki z imenom Melania. (Nedelo, 22. 1. 2017: 24) 
Ni se še zgodilo, da bi prestižna revija Vogue, ki velja za najbolj priznano modno revijo na svetu, kaj šele v ameriški izdaji, pisala o Sevnici in Sloveniji. Tokrat je bilo tako. V spletni izdaji 23. januarja je novinarka Liana Satenstein poročala o slovenskem ponosu na novo ameriško prvo damo, ki prihaja iz Sevnice, "majhnega slikovitega kraja", kot pravi. Omenjala je tudi izdelke z njenim imenom, od razvpitega lončka medu z njenim portretom, torte do koščka mila vijolične barve z vonjem po sivki /.... (Nedeljski dnevnik, 25. 1. 2017: 28)

Številni lokalni pridelovalci so uporabili »Melanio« kot prvo damo in ustvarili številne izdelke, povezane z njo, denimo natikače »Melania«, v medijih pa so bili objavljeni številni recepti za jedi z njenim imenom. Kot je denimo poročalo Nedelo (22. 1. 2017: 24), nedeljski časopis z najvišjo naklado, so lokalni pridelovalci iz Sevnice izumili cel nabor oznamčene hrane, kot denimo jagodno sladico, jabolčno pito in burger, poimenovane po Melaniji, da bi s tem privabili slovenske in tuje turiste, mediji pa so o tem nereflektirano poročali. Tovrstno poročanje ni imelo namena znamčenja in ustvarjanja slovenske nacije, vendar pa sta implicitni posledici takšnega spontanega poročanja dve: »Melanio« so oznamčili kot lokalno in nacionalno

476 tržno znamko, hkrati pa so interpelirali bralce kot nacionalne subjekte skozi spontan, vsakdanji nacionalizem, ki so ga reproducirali; "Novinarji svetovnih medijskih hiš so si kar podajali kljuke lokalov, kjer je mogoče poskusiti Melanijine dobrote." (Nedelo, 22. 1. 2017: 24).

Tiskani mediji v Sloveniji skozi znamčenje "Melanie» (kot nacionalne in lokalne znamke) torej sodelujejo pri trženju nacionalne in lokalne pokrajine in kulture, od zgodovine do kulinarike. Čeprav mediji le posnemajo oziroma sledijo lokalnim ponudnikom novih proizvodov, povezanih z »Melanio«, je njihova vloga pri konstruiranju in znamčenju nacije ključna, medtem ko aktivno sodelujejo v delovanju spontanega, banalnega, popularnega nacionalizma, čigar cilj je ustvariti skupnost kot nacijo s pomočjo banalnih, vsakdanjih praks in stvari, ki jih jemljemo za samoumevne, od lokalne pokrajine do hrane, če uporabimo Edensorove besede (2002).

\section{Sklep}

Naša analiza je pokazala, da igrajo slovenski tiskani mediji pomembno vlogo v strategijah znamčenja nacije, s pomočjo podob »Melanie« pa spontano reproducirajo vsakdanji komodificirani nacionalizem, ko konstruirajo Melanio kot slovensko nacionalno tržno znamko. Ugotovili smo, da vse tri diskurzivne strategije, ki smo jih izpostavili v članku, spodbujajo specifičen tip nacionalizma, ki ga mediji tesno povezujejo s komercialno usmerjenimi praksami. V primerjavi s tradicionalnim, modernističnim projektom 
etnicizacije nacije je ta postmoderni projekt znamčenja nacije $\mathrm{v}$ slovenskih medijih usmerjen bolj k marketizaciji nacije in bolj služi dvigu slovenske nacije iz anonimnosti in majhnosti kot procesu grajenja naroda ali kolektivni identifikaciji bralk in bralcev z narodom. V medijskem diskurzu o »Melanii« so prav tako komodificirana nacionalna občutenja, ki delujejo kot banalna (Billig, 1995) oziroma kot mehka oblika nacionalizma. Sprožena čustva napram "Melanii« dovoljujeo bralcem in bralkam specifično nacionalno intimnost in medtem ko je "Melania« Oznamčena kot slovenska nacionalna znamka $\mathrm{v}$ medijih, so komodificirana tudi globoka nacionalna čustva bralcev-potrošnikov, saj se skuša Slovenija in čustva do nje prodati kot potrošniški izdelek, to pa nacionalizem spreminja $\mathrm{v}$ komercialno prakso.

$\mathrm{Na}$ osnovi študije ugotavljamo tudi, da so bili v literaturi o znamčenju nacije mediji večinoma obravnavani zgolj kot posredniki med drugimi akterji v kampanjah znamčenja. V članku zato izpostavljamo pomembno ugotovitev, in sicer vlogo medijev kot samostojnih akterjev, kot dejavnikov spontanega znamčenja nacije $\mathrm{v}$ primeru Melanie Trump. Posledično opozarjamo, da je konceptualizacija znamčenja nacije kot prakse vlad, podjetij in specialistov za trženje in odnose z javnostmi preozka. Pri tem pokažemo, da $v$ tem oziru niso relevantni le večji medijski konglomerati, kot so BBC, CNN in National Geographic, kot sta predlagala Bolin in Stahlberg (2015: 3077), pač pa tudi manjši, nacionalni mediji od popularnih revij do nacionalnih dnevnikov.

V naši analizi ni bilo opaznejših razlik $\mathrm{v}$ poročanju niti med različnimi medijskimi žanri in tipi medijev niti med obema obdobjema, vključenima $\mathrm{v}$ analizo, saj so bile tako $\mathrm{v}$ popularnih revijah kot $\mathrm{v}$ resnih časnikih pred in po inavguraciji prisotne različne strategije znamčenja. V obeh obdobjih "Melania« nastopa kot vzdržljivi označevalec nacionalne energičnosti in pripadnosti, pri čemer hkrati promovira ekonomsko rast. Tiskani mediji v Sloveniji tako uporabljajo "Melanio«, da bi zgradili razkošno nacionalno blagovno znamko, ki bi promovirala Slovenijo različnim občinstvom.

Pri tem pa je zanimivo, da sodeč po enem zadnjih medijskih zapisov, znamčenje »Melanie« $\mathrm{v}$ zadnjih letih v slovenskih medijih ni bilo pretirano uspešno v smislu ekonomskih pridobitev. Številne turistične agencije so namreč ponujale izlete $\mathrm{v}$ »Melaniin« domači kraj, a jim ni uspelo pritegniti zadostnega števila turistov, ki so obiskovali bolj uveljavljene turistične atrakcije v Sloveniji. Tovrstni podatki pričajo o tem, da ustvarjanje »Melanie « kot slovenske nacionalne znamke ni uspelo nagovoriti globalnih občinstev in privabiti večjega števila tujih turistov, uspešneje pa so te reprezentacije nagovorile domače, nacionalno občinstvo predvsem z vzbujanjem globokih nacionalnih občutenj prek reprezentacij "Melaniinih" etničnih korenin. Zamišljanje skupnega in enotnega slovenskega naroda, vzbujanje globokih občutenj ponosa in trženja nacije lokalnim občinstvom s pomočjo 
medijskih reprezentacij »Melanie« tako ostajajo ključne vloge, ki jih igrajo mediji v komodifikaciji in komercializaciji slovenskega nacionalizma.

\section{LITERATURA}

Aronczyk, Melissa (2013): Branding the nation: The global business of national identity. Oxford: Oxford University Press.

Balabanis, George, Adamantios Diamantopoulos, Rene Dentiste Mueller in T. C. Melewar (2001): The Impact of Nationalism, Patriotism and Internationalism on Consumer Ethnocentric Tendencies. Journal of International Bussiness Studies 32 (1): $157-175$.

Billig, Michael (1995): Banal Nationalism. London: Sage.

Bodnar, John (1994): Remaking America: Public Memory, Commemoration, and Patriotism in the Twentieth Century. Princeton: Princeton University Press.

Bolin, Göran in Per Ståhlberg (2010): Between Community and Commodity: Nationalism and Nation Branding. V: Anna Roosvall in Inka Salovaara-Moring (ur.), Communicating the Nation: National Topographies of Global Media Landscapes, 79-101. Göteborg: Nordicom.

Bolin, Göran in Per Ståhlberg (2015): Mediating the Nation-State: Agency and the Media in Nation-Branding Campaigns. International Journal of Communication 9: 3065-3083.

Bolin, Göran in G. Miazhevich (2018): The soft power of commercialised nationalist symbols: Using media analysis to understand nation branding campaigns. European Journal of Cultural Studies 21 (5): 527-542.

Castelló, Enric in Sabina Mihelj (2018): Selling and consuming the nation: Understanding consumer nationalism. Journal of Consumer Culture 18 (4): 558-576.

Castile, George Pierre (1996): The Commodification of Indian Identity. American Anthropologist 98 (Dec.): 743-749.

Cheng, Mingming in Anthnony Ipkin Wong (2014): Tourism and Chinese popular nationalism. Journal of Tourism and Cultural Change 12 (4): 307-319.

Dinnie, Keith (2016): Nation Branding: Concepts, Issues, Practice. London and New York: Routledge.

Eade, John (1990): Nationalism and the quest for authenticity: The Bangladeshis in Tower Hamlets. Journal of Ethnic and Migration Studies 16 (4): 493-503.

Edensor, Tim (2002): National Identity, Popular Culture and Everyday Life. London: Bloomsbury.

Fan, Ying (2006): Branding the nation: What is being branded? Journal of Vacation Marketing 12 (1): 5-14.

Frew, Elspeth in Leanne White (2011): Tourism and National Identities: An International Perspective. New York: Routledge.

Gray, Clive (2007): Commodification and Instrumentality in Cultural Policy. International Journal of Cultural Policy 13 (2): 203-215.

Heller, Monica (2010): The Commodification of Language. Annual Review of Anthropology 39: 101-114.

Hoefte, Rosemarijn, in Veenendaal, Wouter (2019): The Challenges of NationBuilding and Nation Branding in Multi-Ethnic Suriname. Nationalism and Ethnic Politics 25 (2): 173-190. 
Kaneva, Nadia (2018): Simulation nations: Nation brands and Baudrillard's theory of media. European Journal of Cultural Studies 21 (5): 631-648.

Kaneva, Nadia in Delia Popescu (2011): National identity lite: Nation branding in post-Communist Romania and Bulgaria. International Journal of Cultural Studies 14 (2): 191-207.

Kania-Lundholm, Magdalena (2012): Re-Branding a Nation Online: Discourses on Polish Nationalism and Patriotism - Doctoral dissertation. Stockholm: Uppsala University. Dostopno prek http://www.diva-portal.org/smash/get/ diva2:552055/FULLTEXT01.pdf, 11. 9. 2019.

Kim, Jinwon in Meebae Lee (2018): Nation branding or marketization?: K-Classic and Korean classical musicians in an era of globalization. International Journal of Cultural Policy 24 (6): 756-772.

Konečnik Ruzzier, Maja (2012): Developing brand identity for Slovenia with opinion leaders. Baltic Journal of Management 7 (2): 124-142.

Lahusen, Christian (1993): The aesthetic of radicalism: the relationship between punk and the patriotic nationalist movement of the Basque country. Popular Music 12 (3): 263-280.

Li H (2009) Marketing Japanese Products in the Context of Chinese Nationalism. Critical Studies in Media Communication 26 (5): 435-456.

Luthar, Breda in Andreja Trdina (2015): Nation, Gender, Class: Celebrity Culture and the Performance of Identity in the Balkans. Slavic Review 74 (2): 265-287.

Nussbaum MC (2010): Patriotism and Cosmopolitanism. V: Garret Wallace Brown in David Held (ur.), The Cosmopolitanism Reader, 155-162. Cambridge: Polity Press.

O'Connor, Barbara (2012): Spaces of Celebrity: National and Global Discourses in the Reception of TV Talent Shows by Irish Teenagers. Television \& New Media 13 (6): 568-583.

Pamment, James in Cecilia Cassinger (2018) Nation branding and the social imaginary of participation: An exploratory study of the Swedish Number campaign. European Journal of Cultural Studies 21 (5): 561-574.

Prideaux, Jillian (2009): Consuming icons: nationalism and advertising in Australia. Nations and Nationalism 15 (4): 616-635.

Ramaswamy, Sumathi (2010): The Goddess and the Nation: Mapping Mother India. Durham and London: Duke University Press.

Roosvall, Anna in Inka Salovaara Moring (2010): Introduction. V: Anna Roosvall in Inka Salovaara-Moring (ur.), Communicating the Nation: National Topographies of Global Media Landscapes, 9-21. Göteborg: Nordicom.

Shepherd, Robert (2002): Commodification, Culture and Tourism. Tourist Studies 2 (2): 183-201.

Ståhl berg, Per in Göran Bolin (2016): Having a soul or choosing a face? Nation branding, identity and cosmopolitan imagination. Social Identities, Journal for the Study of Race, Nation and Culture 22 (3): 274-290.

Szondi, György (2007): The Role and Challenges of Country Branding in Transition Countries: The Central and Eastern European experience. Place Branding and Public Diplomacy 3 (1): 8-20. 
Tan, Kok-Chor (2004): Justice without Borders: Cosmopolitanism, Nationalism, and Patriotism. Cambridge: Cambridge Universoty Press.

Valaskivi, Katja (2016): Cool Nations: Media and the Social Imaginary of the Branded Country. London in New York: Routledge.

Varga, Somogy (2013): The politics of Nation Branding: Collective identity and public sphere in the neoliberal state. Philosophy and Social Criticism 39 (8): $825-845$.

Vidmar Horvat, Ksenija (2019): Tourist Patriotism: From Ethnicization to Marketization of the Nation (neobjavljen članek).

Vitic, Andriela in Greg Ringer (2007): Branding post-conflict destinations: Recreating Montenegro after the disintegration of Yugoslavia. Journal of Travel and Tourism Marketing 23 (2-4): 127-137.

Volčič, Zala (2008): Former Yugoslavia on the World Wide Web: Commercialization and Branding of Nation-States. International Communication Gazette 70 (5): 395-413.

Volčič, Zala (2011): Branding Slovenia: "You Can’t Spell Slovenia Without Love ..." V: Nadia Kaneva (ur.), Branding Post-Communist Nations: Marketizing National Identities in the "New" Europe, 147-167. New York: Routledge.

Volčič, Zala in Mark Andrejevic (2011): Nation Branding in the Era of Commercial Nationalism. International Journal of Communication 5 (1): 598-618.

Wang, Jian (2006): The Politics of Goods: A Case Study of Consumer Nationalism and Media Discourse in Contemporary China. Asian Journal of Communication 16 (2): 187-206.

VIRI

Finance (2016): (10. 11.): 3.

Grazia (2016): (1. 11.): 31.

Mladina (2017): (20. 1.): 54

Nedelo (2016): (13. 11.): 5.

Nedelo (2016): (13. 11.): 9.

Nedelo (2017): (22. 1.): 24.

Nedeljski dnevnik (2017): (25. 1.): 28.

Obrazi (2017): (9. 2.): 8.

Primorske novice (2017): (20. 1.): 11.

Reporter (2016): (14. 11.): 3.

Reporter (2016): (14. 11.): 16.

Reporter (2016): (14. 11.): 46.

Reporter (2017a): (23. 1.): 3.

Reporter (2017b): (6. 2.): 58.

Slovenske novice (2016): (10. 11.): 2.

Slovenske novice (2017): (24. 1.): 10.

Svet24 (2017): (21. 1.)

Večer (2016a): (10. 11.): 24.

Večer (2016b): (14. 11.): 2.

Vklop (2016): (20. 10.) 